\author{
Military Technical College \\ Kobry El-Kobbah, \\ Cairo, Egypt.
}

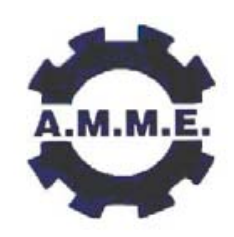

$13^{\text {th }}$ International Conference on Applied Mechanics and Mechanical Engineering.

\title{
DETECTING STICK-SLIP OCCURRENCE BY NEAR FIELD NOISE MEASUREMENTS
}

\author{
GHAZY*M.R.A. and EL-HADY** A.M.
}

\begin{abstract}
The present study is concerned with evaluating the pin-on-disk test rig usage and the measurements conducted in recognizing the occurrence of stick-slip phenomenon. The test rig consists of two separate blocks to ensure that the vibration of the elastic disk and the emitted noise are completely adverted to friction between the moving pin and the stationary steel disk.

The occurrence of stick slip is clearly picked up using the near field noise measurements. It can be distinguished from the vibration signal as high consecutive spikes, but the existence of these spikes is clearer and more definite in the noise signature.
\end{abstract}

\section{KEY WORDS}

Pin on Disk, Friction, Induced vibration, Noise, Stick, Slip.

* Department of Mechanical Engineering Design, Faculty of Engineering, Zagazig University.

** Department of Space Science, National Authority of Remote Sensing and space Science, Egypt. 


\section{INTRODUCTION}

The vibration and noise induced by dry friction are overwhelmed by non linearity factors. One of the main origins of non linearity is the variation in the coefficient of friction. This variation is attributed to many factors such as change of pin's velocity, occurrence of stick slip, change of the acting normal force due to pin's vibration in the normal (vertical) direction. The remarkable variation of contacting surface topology due to occurrence of abrasive and adhesive wear has a big contribution to the variation occurring in the friction coefficient.

Wave transmission and vibration modes of the disk and the pin also have considerable effect on the measured vibration signature.

The friction characteristics resulting from the motion of one surface over another can often strongly influence the behavior and operational efficiency of many physical systems. It is often cited that about $40 \%$ of the frictional problems in industries are due to vibrations induced by friction

Friction-induced vibration, chatter, and squeal are serious problems in many industrial applications. Many experimental and analytical studies have led to insight on the factors contributing to brake squeal or to the improvement of squeal in disk brakes of a specific type or in a particular making and model of automobile. Experimental studies have accumulated a wealth of information about the nature of squeal, the vibration modes therein, the wear of brake components, and frictional interactions in brakes. Analytical studies have provided useful insights into how friction laws, geometry and the dynamics of brake components can lead to squeal or instability in simple models of disk brakes. Finite elements have been used to try to extend these insights to more accurate brake models. There is a large number of models devoted to brake squeal.

Early work of Earles and Lee [1] featured experiments in which a disk; contacted by a pin which is supported by a flexible cantilever, is spun at a constant speed. They stated that the system stability is dependent on the coefficient of friction. Earles and Badi [2] and Earles and Chambers [3 and 4] used pin on disk systems in which two pins were acting on the disk to investigate and quantify the sprag-slip mechanism for squeal. The investigations performed consisted of examining how the damping influenced squeal. They found that damping in the pin assembly (corresponding to damping of the brake pad assembly in a disk brake) could enlarge the unstable regions under certain circumstances, while disk damping always reduced these regions.

The experimental tests on a pin-on disk type sliding system by Dweib and D'Souza [5] have indicated that, for a constant sliding speed, the friction force depends on the normal load. They showed that according to the value of the normal load, there are four different regimes; namely: steady-state, non-linear, transient friction and self-excited vibration regions.

Ibrahim [6], addressed friction and contact mechanics. He summarized the principal results pertaining to factors affecting friction between sliding surfaces. According to him, the occurrence of stick-slip is unpredictable and is attributed to the fact that the slope of the friction-speed curve is not constant but varies randomly with contamination, surface finish, miss-alignment of sliding surfaces, and other factors. He classified vibrations in the mechanical systems into three categories: stick-slip, vibrations induced by random 
surface irregularities and quasi-harmonic self-excited oscillations. Ibrahim et al. [7] measured the average normal and friction forces acting on a friction element (which was in the form of a pin) which was placed in contact with a rotating disk. Both the rotation speed and direction of the disk rotation were variable, and their tests were performed at constant rotational speeds. They noted several interesting features. Most notably, neither the normal force nor the kinetic coefficient of friction was constant. In fact, these authors reported that the friction and normal forces acting on the friction element are random and non-Gaussian processes. Ibrahim [8] has discussed role of random vibrations in the generation of brake noise.

Considering the acoustics of friction-induced vibration, an illuminating discussion has been reported by Akay [9]. He attempted to bring together acoustics and friction by exposing many of the topics that are common to both fields. He affirmed that modeling of friction induced vibrations and friction damping in mechanical systems requires an accurate description of friction for which only approximations exist.

Chan et al. [10] presented a study of brake squeal which is based on the splitting of the frequency of the doublet modes in the symmetric disk when a friction force is applied, this splitting could lead to flutter which is associated to brake squeal. They considered a clamped elastic annular disk which is loaded (at a discrete number of points) by a tangential follower force traction which is related to the normal pressure by the coefficient of friction.

Mottershead and Chan [11,12] addressed the tendency of a disk to generate noise when the natural frequencies of in-plane and bending vibrations exist close to each other as well as self-excited vibrations of a circular plate with friction forces acting on its edge to model squeal in drum brakes.

Ouyang et al. [13-15] considered the flexibilities of the rotor and the brake pad assemblies. As these bodies deform during the vibrations of the disk brake system, a variation in the normal forces between them occurs. This in turn causes a variation in the friction forces even if the coefficient of friction is constant.

Kinkaid et al. [16] presented a detailed revision of the pin on disk friction models. He demonstrated a revision of most of the models that have appeared in the literature, and summarized some of them. He also pointed out the inter-relationships between these models. In these models, a linear stability analysis was performed in order to predict the onset of instability which; according to most researchers, has been correlated to the occurrence of squeal.

For the typical test rigs usage, such as those used by [17] and [18], the effect of the disk elasticity is not included since the disk is usually supported to a heavy rigid base. Fig. 1 shows a typically used pin on disk arrangement. In these test rigs, the frame used supports all parts: the pin arrangement, the driven disk and the driving motor. Thus measured vibration (of the pin) would include traces due to vibration of the driving arrangement.

\section{TEST RIG}

The objective of the test rig is to enable measuring both noise and vibration of the disk 


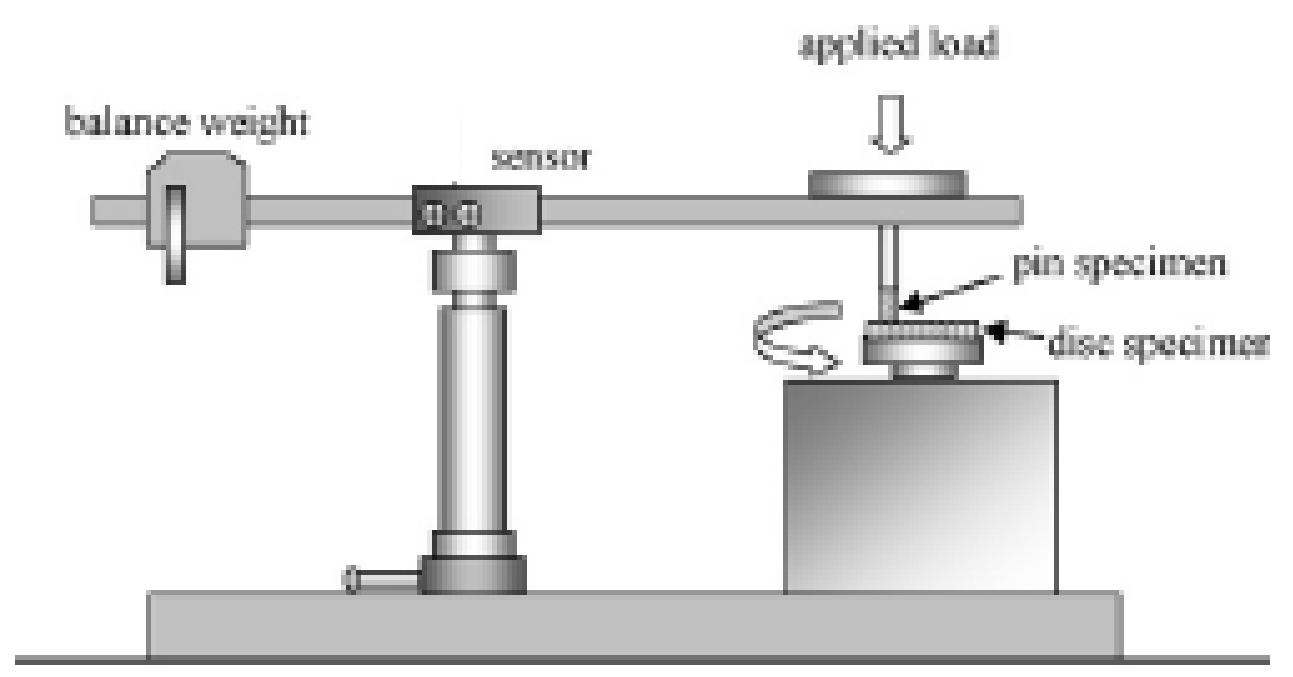

Figure 1: A typical pin on disk test rig arrangement used (copied from[17]).

in three perpendicular axes induced by friction. These directions are: vertical/ normal (perpendicular to disk surface), horizontal (tangential to the locus of the pin) and radial (perpendicular to the tangential direction, in plane of the disk surface). Fig.2 shows the test rig arrangement.

The testing apparatus is designed to study the friction induced vibration of the disk at high loads and speeds. Loads varying from $25[\mathrm{~N}]$ to $75[\mathrm{~N}]$ applied on the pin in the vertical direction, can be tested. The present design also allows testing four pin linear velocities; these are, 2, 2.6, 4 and $5.2[\mathrm{~m} / \mathrm{s}]$.

The pin; fixed to a pulley, is belt driven using a $1.1[\mathrm{~kW}]$ electric motor. The pulley arrangement includes a greased sliding bearing to minimize vibration. Different from most of the reported pin on disk test rigs (in which the rotating plate is directly fixed on the motor shaft), this test rig incorporates two separate heavy blocks which are used to support the test rig. On the first one the disk and pin arrangement is fixed. The second block is used to hold the driving motor. This arrangement ensured negligible vibration transmitted to the disk from all other sources but the pin.

The measured vibration and noise signals when the arrangement is working with no pin-disk contact, show no (negligible) vibration and noise traces due to the driving system. This ensures that the measured vibration and noise signals will be like that because of nothing but that generated due to friction between the moving pin and the fixed disk.

The normal load is changed using steel plates bolted to the pulley driving the pin. Measuring the vibration of the disk in the three perpendicular axes is enabled through fixing a steel cube; of $15[\mathrm{~mm}]$ side length, to the plate.

A 2.6[gm] B\&K accelerometer type 4375 of $4.78[\mathrm{mV} / \mathrm{g}]$ sensitivity, is used for picking up the disk vibration, and a B\&K microphone type 4189 is used for picking the generated noise signal. An infra red diode with emitter and acceptor is used to pick a timing signal. 
It should always be remembered that the measured vibration signal; picked up at a specific fixed location on the disk, is due to excitation induced by friction of the pin at a point somewhere on its locus.

The signal from the infra red diode, representing the timing and triggering signal is fed directly to a four channel Tektronix digital oscilloscope type TDS200. The signals from the accelerometer and the microphone are fed to the oscilloscope through two B\&K charge amplifiers. The acquired signals are transferred to a computer in both photographic and digital forms for storage and further analysis.

A sampling rate of 25000[sample/s] is used. This ensures a free of anti-aliasing amplitudes up to a frequency of $6[\mathrm{kHz}]$. The three used pins are, steel $(H . R=99.67)$, copper $(H . R=98)$ and aluminum $(H . R=96.83)$.

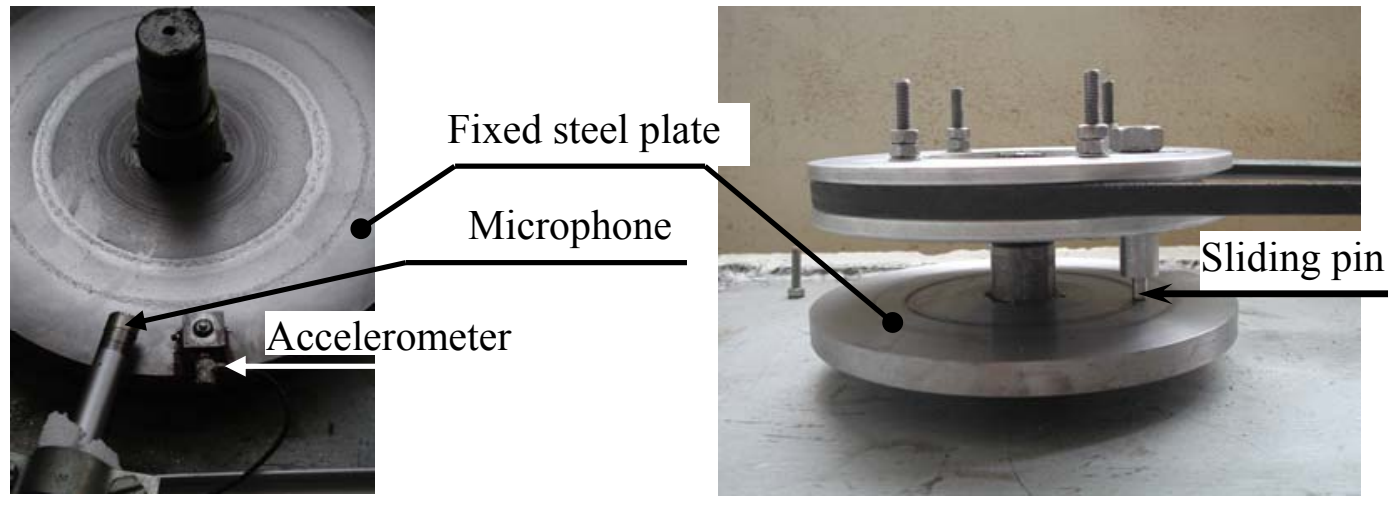

Figure 2: Test rig arrangement.

\section{RESULTS AND DISCUSSIONS}

The investigation into friction induced noise and vibration is based on using a fixed elastic steel disk in contact with a moving pin. The effects of changing the contact parameters such as: the pin material, the pin speed and the normal load, on the disk vibration and the emitted noise are discussed.

Measurements are conducted three times for each test condition. Small variations; which were neglected, in the amplitude of vibration were noticed in cases where stickslip phenomenon was not detected. In which case the first measurement is reported. In cases where stick-slip phenomenon is detected, the variation in amplitudes of the spikes resulting from the slipping of the pin are appreciably varying, in which case the three measured vibration signals were averaged and reported.

In all figures, the vertical axes represent the vibration amplitude. The amplitude is left in volts, because the settings of the charge amplifier is left the same during the testing procedure. 


\section{Effect of Pin Material on Induced Disk Vibration}

Three pins of the same geometric shape, but of different materials are used. The used pin's materials are steel, copper and aluminum. Fig. 3 shows a comparison between the disk vibration, measured in the vertical direction, induced by friction between the fixed steel disk and the moving pins at pin's linear velocity of $5.2[\mathrm{~m} / \mathrm{s}]$. The figure shows that, at a specific speed, the disk induced vibration because friction is high for the steel pin and low for the copper pin.

\section{Effect of Pin Speed on Induced Disk Vibration}

Figure 4 shows the disk vibration, measured in the vertical direction, due to the moving steel pin at two different pin's speeds; namely $4[\mathrm{~m} / \mathrm{s}]$ and $5.2[\mathrm{~m} / \mathrm{s}]$. The same comparison, due to moving the copper and aluminum pins, show the same attitude. In general, increasing the pin velocity increases the amplitude of vibration in the specific direction.

\section{Effect of Normal Load on Induced Disk Vibration}

Figures 5 shows the vibration in the vertical direction for the aluminum pin, at a pin velocity of $5.2[\mathrm{~m} / \mathrm{s}]$ at different normal loads. The figure shows that the vibration generally increased with increasing the applied normal force. The same conclusion generally applies for all cases.

\section{Comparison Between Induced Disk Vibration in the Three Directions}

Figure 6 shows a typical comparison between the induced vibration signals measured in the three perpendicular directions at a given speed and normal load. Generally, the vibration levels in the vertical direction are higher than that in the horizontal direction, and that the level of the horizontal vibration is higher than that in the radial direction.

\section{RECOGNITION OF STICK-SLIP}

Simultaneous measurement of the disk vibration and the near field friction induced noise, reveal the instant when the stick-slip phenomena occurs. At that moment, the induced noise is momentarily zero. That moment is not clearly identified on the vibration signal. This is attributed to the fact that the disk will continue to vibrate even though the exciting friction force is momentarily zero. Occurrence of stick phase will momentarily induce no noise since there is no momentarily friction between the pin and the disk.

Figure 7 shows both the measured vibration and noise signals on the same time basis for the steel pin at linear pin's velocity of $5.2[\mathrm{~m} / \mathrm{s}]$ and normal load of $40[\mathrm{~N}]$. Many stickslip events can be identified. The arrows show some of the slipping events producing a high spike on the vibration signature and on the noise signature too. Between any two successive slip events, there is a stick event, which produces a substantially low radiated noise. 


\section{CONCLUSIONS}

It is concluded that the vibration amplitude induced by friction is always high in the vicinity of the moving pin. That's to say, this phenomenon is a transient phenomenon that; in general, has local effect on the disk.

Increasing the normal load and pin linear velocity generally increases the induced vibration amplitude. Vibration amplitude induced by friction between the steel disk and a steel pin is the highest. And the amplitude of induced vibration in the vertical direction is the highest compared with that in the horizontal and radial directions.

At high loads or speeds, stick slip phenomenon is predominant. The occurrence of stick slip is clearly identified using the near field measurements of noise signals. It can be distinguished from the vibration signal as high consecutive spikes, but the existence of these spikes is clearer in the noise signature. This may be attributed to the fact that noise due to friction momentarily vanishes as stick occurs.

\section{REFERENCES}

[1] S.W.E. Earles, C. Lee, Instabilities arising from the frictional interaction of a pindisk system resulting in noise generation, Transactions of the American Society of Mechanical Engineers Journal of Engineering for Industry, 98 (1) (1976) 8186.

[2] S.W.E. Earles, M. Badi, Oscillatory instabilities generated in a double-pin and disk undamped system: a mechanism of disk-brake squeal, Proceedings of the Institution of Mechanical Engineers C 198, (1984) 43-49.

[3] S.W.E. Earles, P.W. Chambers, Predicting some effects of damping on the occurrence of disk-brake squeal noise, in: ASME Dynamic Systems and Control Division, Vol. 1, ASME, New York, (1985), 317-323.

[4] S.W.E. Earles, P.W. Chambers, Disk brake squeal noise generation: predicting its dependency on system parameters including damping, International Journal of Vehicle Design, 8 (1987) 538-552.

[5] A.H. Dweib and L.T. D'Souza, Self-exited vibrations induced by dry Friction, Part I: Experimental study, Journal of Sound and Vibration, 137, (1990), 163-190.

[6] R. A. Ibrahim, Friction-induced vibration, chatter, squeal, and chaos; Part I: Mechanics of Friction; Part II: Dynamics and modeling, ASME, Journal of Vibrations and Acoustics, 49. (1992), 107-138.

[7] R.A. Ibrahim, S. Madhavan, S.L. Qiao and W.K. Chang, Experimental investigation of friction-induced noise in disk brake systems, International Journal of Vehicle Design 23, (2000), 218-240.

[8] R.A. Ibrahim, Friction-induced noise and related problems in automotive brakes, in: S.G. Pandalai (Ed.), Recent Research Developments in Sound and Vibration, Vol.1, Transworld Research Network, Kerala, India, 2002.

[9] A. Akay, Acoustics of friction, Journal of Acoustic Society of America, 111, (2002), 1525-1548.

[10] S.N. Chan, J.E. Mottershead, M.P. Cartmell, Parametric resonances at subcritical speeds in disks with rotating frictional loads, Proceedings of the Institution of Mechanical Engineers Part C 208 (C6) (1994) 417-425. 
[11] J. E. Mottershead and S. N. Chan, Flutter instability of circular disks with frictional follower loads, Journal of Vibration and Acoustic, 117 (1) (1995) 161163.

[12] H. Ouyang, J. E. Mottershead, D. J. Brookfield, S. James, and M. P. Cartmell, A methodology for the determination of dynamic instabilities in a car disk brake, International Journal of Vehicel Design 23 (3/4), (2000) 241-262.

[13] H. Ouyang, J.E. Mottershead, D.J. Brookfield, S. James, M.P. Cartmell, T. Kaster, T. Treyde, B. Hirst, R. Allen, Dynamic instabilities in a simple model of a car disk brake, Technical Report 1999-01-3409, SAE, Warrendale, PA, 1999.

[14] H. Ouyang, Q. Cao, J.E. Mottershead, and Treyde T, Vibration and squeal of a disk brake: modeling and experimental results, IMechE Journal of Automotive Engineering, 217(10) (2003), 867-875.

[15] H. Ouyang, J.E. Mottershead, A bounded region of disk-brake vibration instability, Transactions of the American Society of Mechanical Engineers Journal of Vibration and Acoustics 123 (4) (2001) 543-545.

[16] N.M. Kinkaid, O.M. O'Reilly and P. Papadopoulos, Automotive disk brake squeal, Journal of Sound and Vibration 267, (2003), 105-166.

[17] Bin-Bin Jia, Tong-Sheng Li and Xu-Jun Liu, Tribological behaviors of several polymer-polymer sliding combinations under dry friction and oil-lubricated conditions, Wear 2007.01.011

[18] Hozumi Goto and Yoshifumi Amamoto, Effect of varying load on wear resistance of carbon steel under unlubricated conditions, Wear 254 (2003) 1256-1266. 

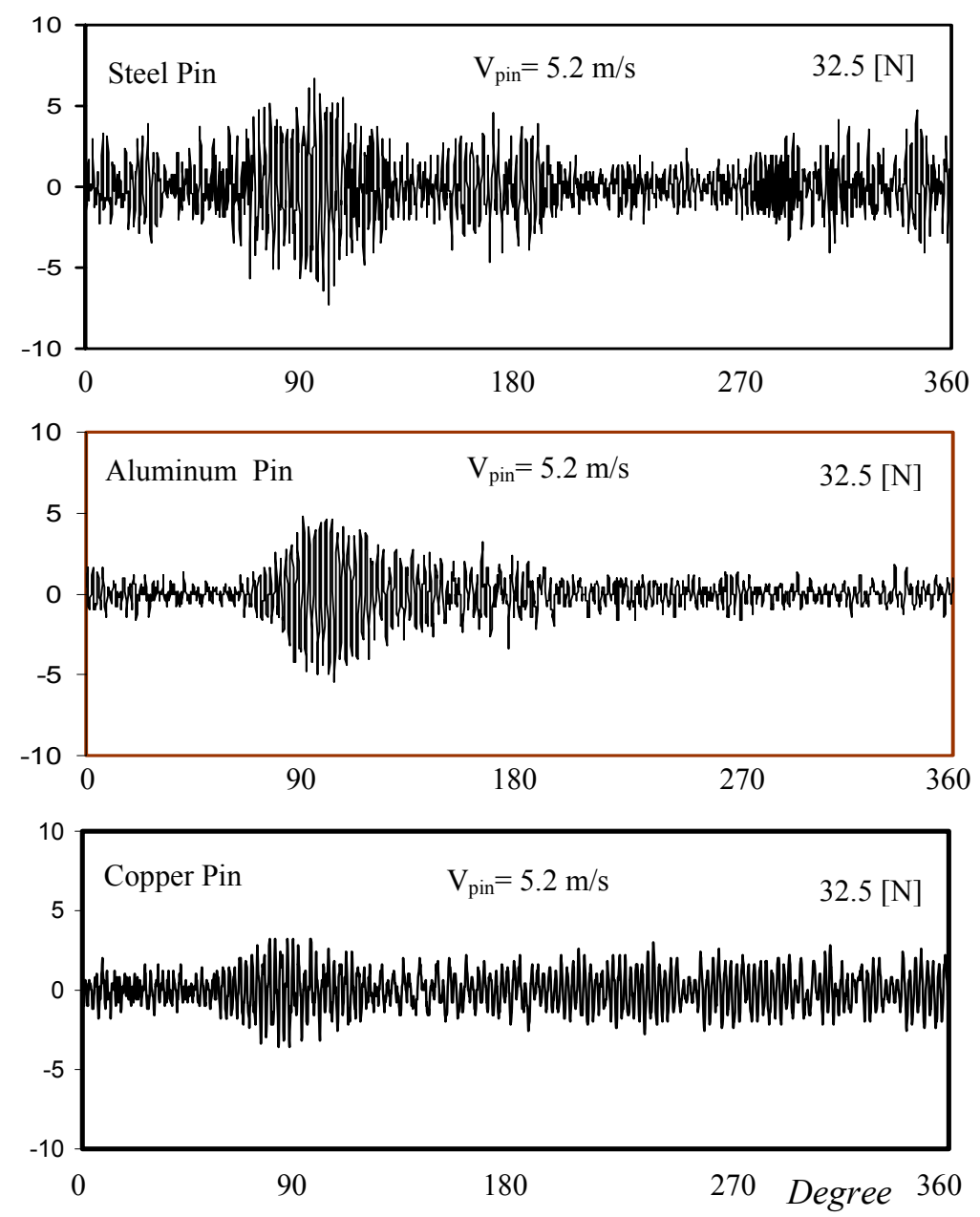

Figure 3 : Effect of varying the contacting pin on the vertical vibration of the disk at pin velocity of $5.2 \mathrm{~m} / \mathrm{s}$ and $32.5 \mathrm{~N}$ normal force.

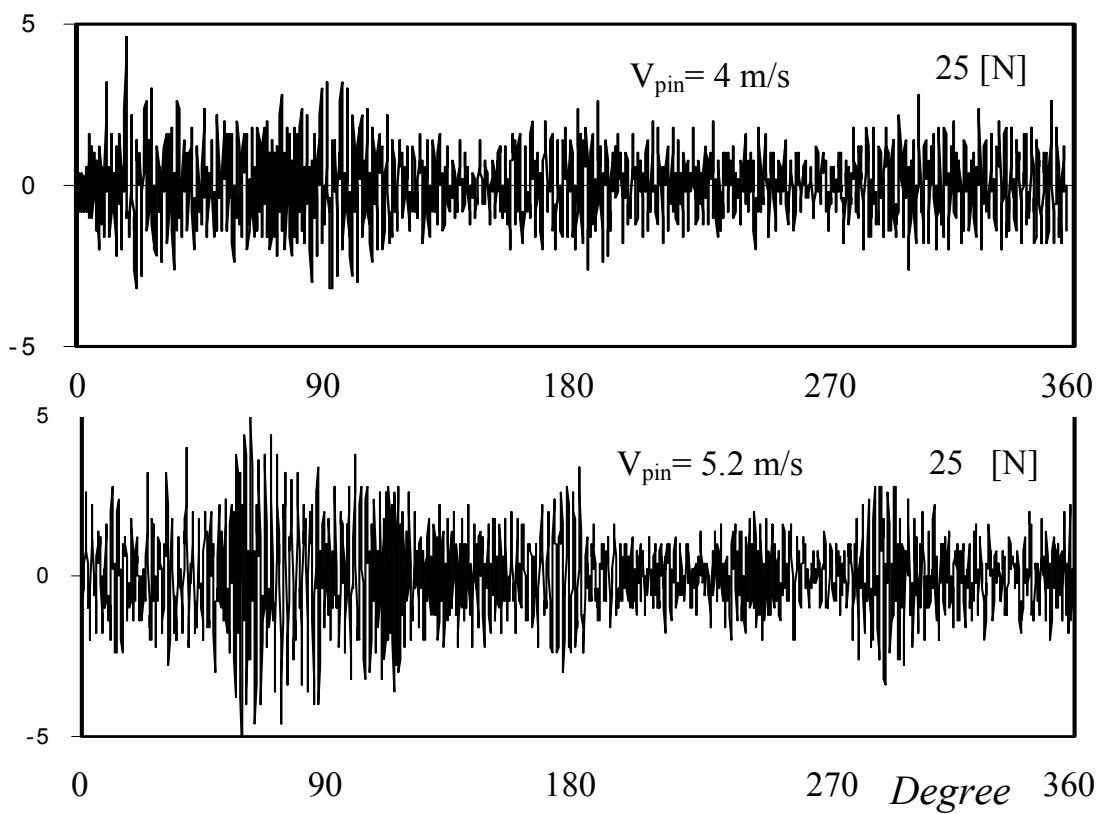

Figure 4 : Effect of varying the steel pin velocity on the vertical vibration of the disk; at the same normal load $(25 \mathrm{~N})$. 

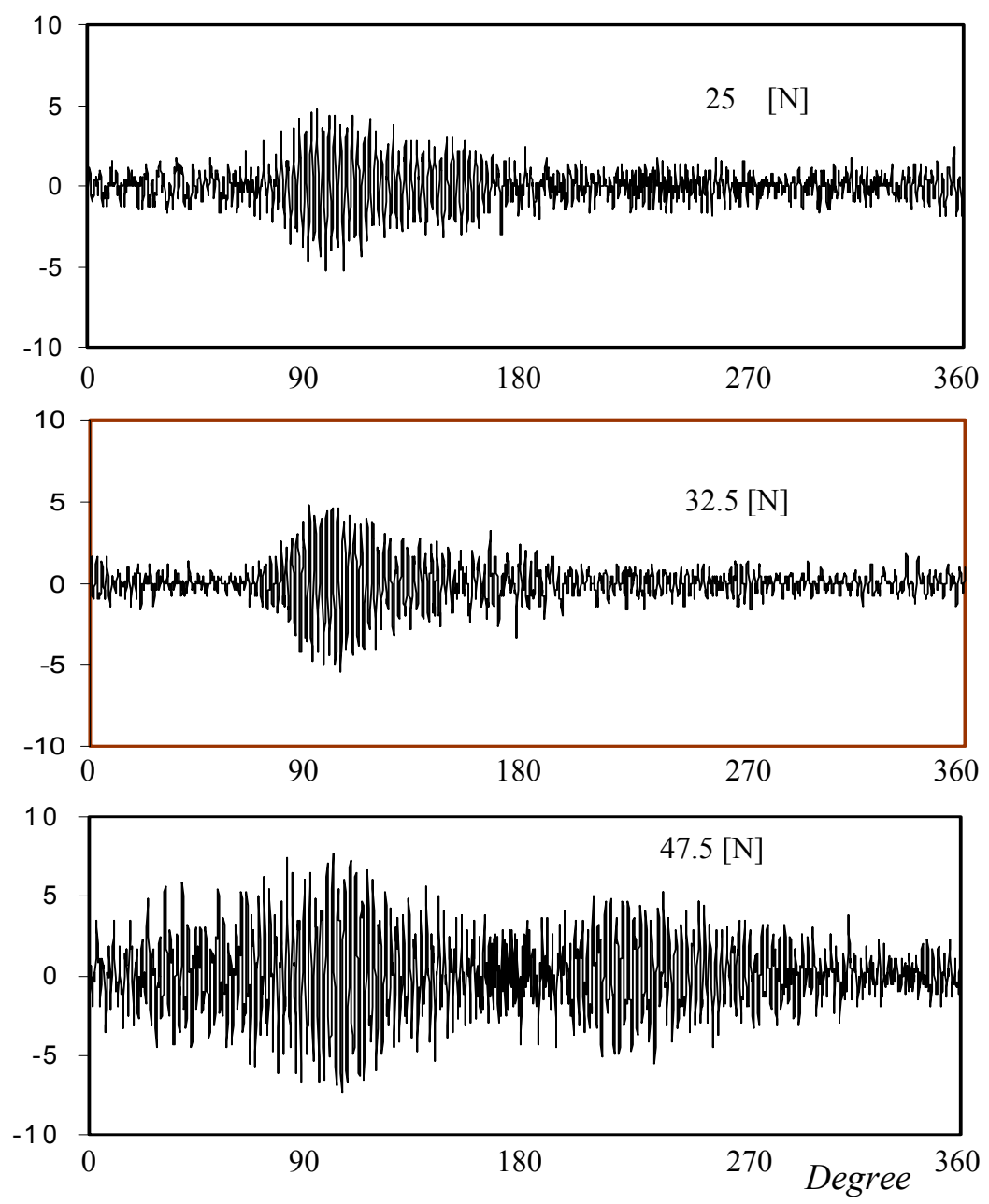

Figure 5 : Measured vertical vibration of the disk using Aluminum pin with linear velocity of $5.2 \mathrm{~m} / \mathrm{s}$ (at different applied normal forces) 

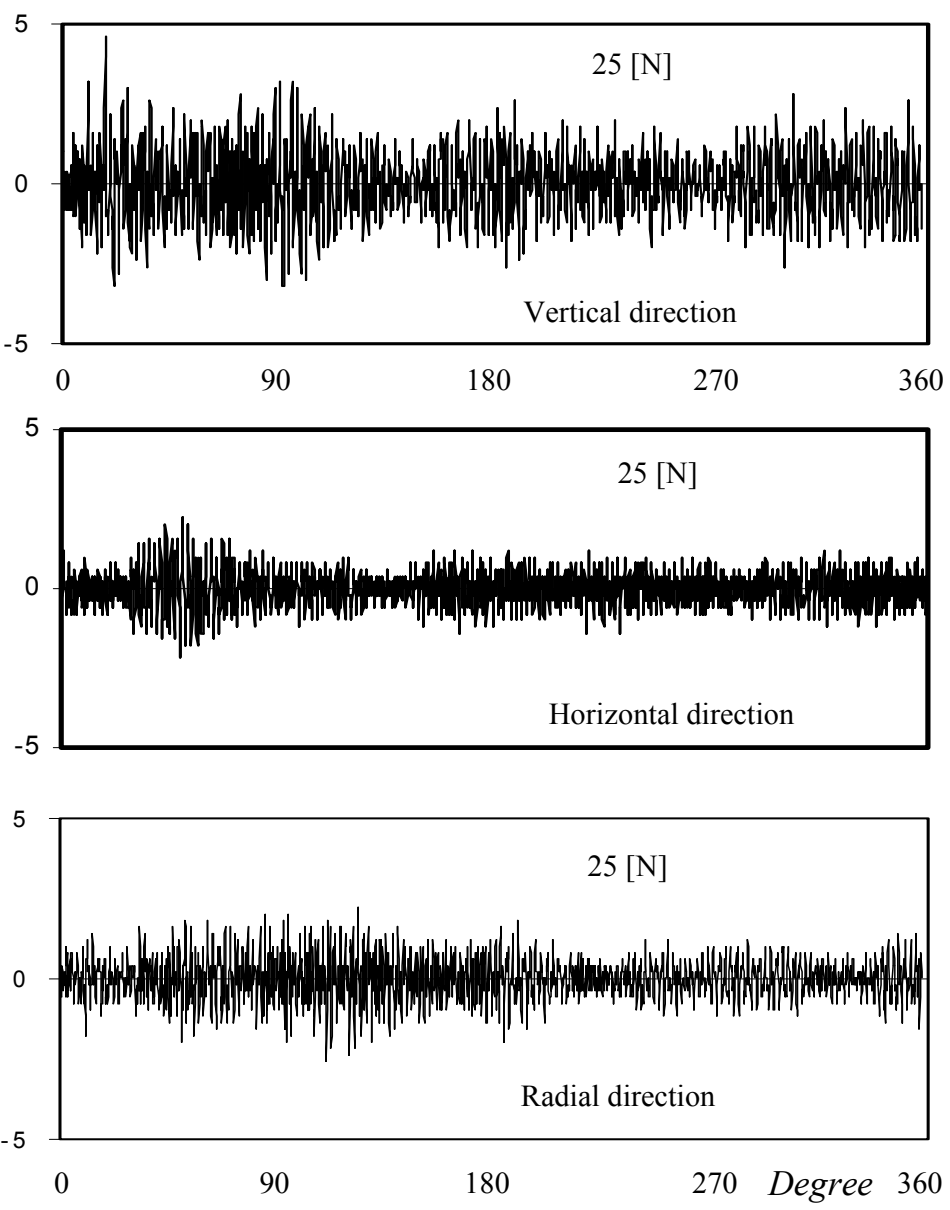

Figure 6 : Comparison between disk vibration in the three directions, when the Steel pin is moving at a velocity of $4[\mathrm{~m} / \mathrm{s}]$; at $25[\mathrm{~N}]$ normal force.
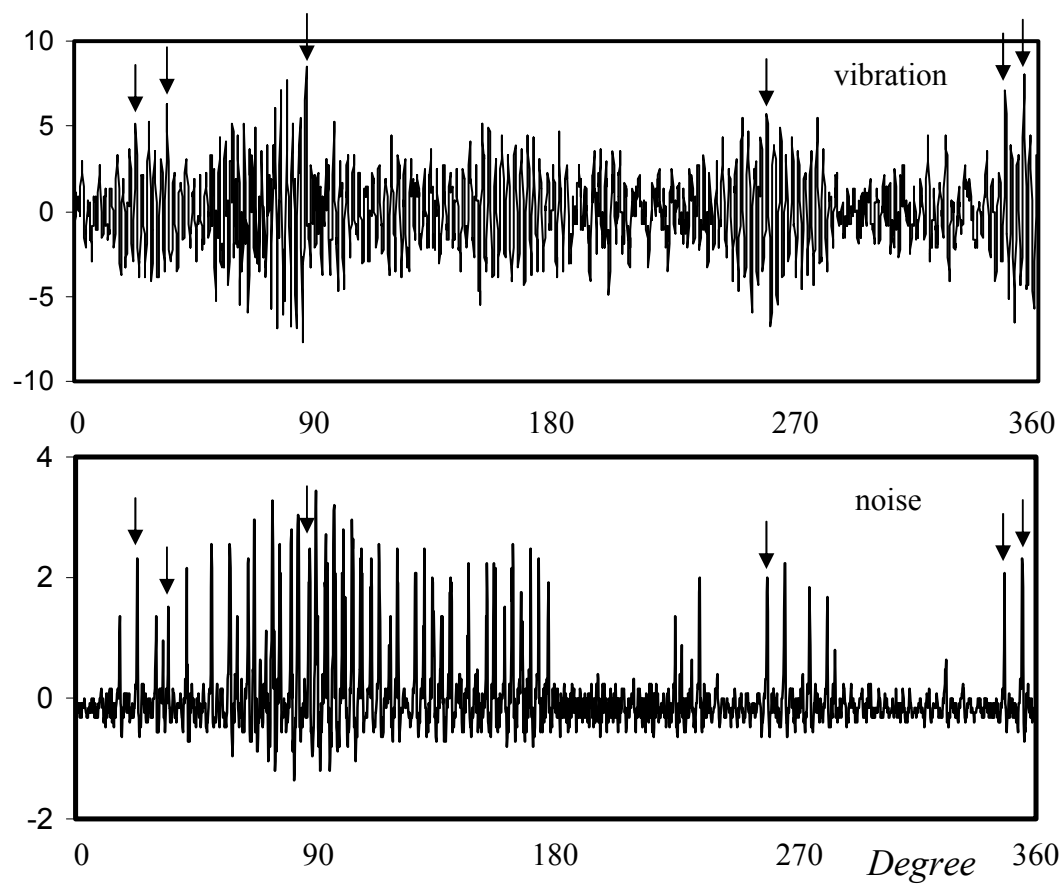

Figure 7 : Measured vertical vibration of the disk and induced noise (Steel pin, normal load $40[\mathrm{~N}], \mathrm{V}_{\text {pin }}=5.2 \mathrm{~m} / \mathrm{s}$ ). 